\title{
Alcances y limitaciones regulatorias ante la precarización global del trabajo
}

\author{
Scope and regulatory constraints to the global precarious work \\ Jorge Valdebenito Allendes*
}

\begin{abstract}
Resumen: El presente trabajo busca problematizar las aperturas y limitaciones de diferentes iniciativas regulatorias sobre el trabajo en el mundo contemporáneo. Tales iniciativas evidencian colisiones con una serie de aspectos formales -como restricciones coercitivas- y fácticos -como negociaciones de vestíbulo o lobby- que reducen su efectividad. Para tales efectos se revisan algunos antecedentes teóricos y prácticos en materia de regulación laboral. Las conclusiones apuntan a la necesidad -y oportunidad- de explorar algunas alternativas de resolución, tales como la defensa de la huelga, la promoción e instauración de la renta básica universal y el control obrero de la producción.
\end{abstract}

Palabras clave: Trabajo; empleo; regulación; precariedad; globalización.

\begin{abstract}
This paper seeks to problematize the openings and limitations of different labor regulatory initiatives in the contemporary world. Such initiatives show collisions with a series of formal aspects - such as coercive restrictions - and factual ones - such as lobbying - that reduce its effectiveness. For this purpose, some theoretical and practical background issues on labor regulation are reviewed. The conclusions point to the need - and opportunity- to explore some resolution alternatives, such as the defense of the strike, the promotion and introduction of the universal basic income, and workers' control of production.
\end{abstract}

Keywords: Work; labour; regulation; precariousness; globalization

Recibido: 14 noviembre 2017 Aceptado: 12 abril 2018

* Chileno. Sociólogo. Doctorando en Estudios Interdisciplinarios, Universidad de Valparaíso, Chile. Becario Conicyt N²1171000. Correo electrónico: jorge.valdebenito@postgrado.uv.cl 


\section{Introducción}

Son múltiples las caracterizaciones de los efectos de la globalización económica sobre el trabajo. No obstante, en el fondo estas son reducibles a partir del diagnóstico del incremento de la precariedad de las condiciones de empleo y trabajo ${ }^{1}$, a lo que se suma la proliferación de nuevas formas de explotación o subsunción del trabajo por parte del capital ${ }^{2}$. Desde el derecho del trabajo se ha erigido una respuesta que busca, mediante la formulación de distintas estrategias de regulación, mitigar los efectos del incremento de la precariedad y explotación laboral. Sin embargo, su alcance posee limitaciones no menores ${ }^{3}$. En el plano de los derechos humanos, cuyos principios se fundamentan en modelos de derecho internacional, estas van desde la ausencia de coercitividad de sus normas, hasta la inviabilidad fáctica de su adopción en espacios jurídicos nacionales ${ }^{4}$.

La externalización y deslocalización productivas son señaladas usualmente como factores clave en el debilitamiento de la solidez de las relaciones laborales en la actualidad. Estos fenómenos han acelerado sus procesos de expansión desde finales de la década de 1970, principalmente $^{5}$. Diferentes Estados han emprendido, desde la neoliberalización de los mercados mundiales, una competencia por atraer inversión de capitales extranjeros, y mejorar sus indicadores de crecimiento económico. Para dicho cometido ejecutan una serie de prácticas y estrategias. Entre estas últimas figuran las sistemáticas reducciones de costos laborales, comprendidas sutilmente como políticas de flexibilidad laboral. Allí, supuestamente por el alto costo de los sistemas de protección social, las empresas deciden deslocalizar sus plantas productivas hacia países con costos laborales menores. Esto explicaría lo que ha significado más tarde la proliferación de los denominados "cuatro dragones del sudeste asiático", correspondientes a Singapur, Hong-Kong, Corea del Sur y Taiwán.

A lo anterior se suman las innovaciones técnicas del capital para eludir toda regulación laboral, por reducida que esta sea. Así lo ilustra la apertura de plantas productivas en aguas internacionales, o factory ships. Operando al margen de toda legislación laboral sostenida por la potestad jurídica de un Estado nacional 6 es escasa la información respecto a las condiciones de trabajo que en dichos lugares se encuentran. Salvo breves notas de prensa que señalan lo difícil que es acceder para investigadores y/o periodistas a tales sitios, se desconoce lo que allí ocurre. Las actividades de los factory ships van más allá de la extracción y procesamiento de material propio de la industria pesquera. También contienen infraestructuras necesarias para la ejecución de procesos industriales de diferentes ramas, como industria tecnológica, textil, automovilística, entre otras.

\footnotetext{
1 Omar Aguilar, Globalización, modelo de desarrollo y trabajo en Chile, Némesis, 4, 2004. Y CECT, Chile: Derechos humanos o barbarie. Informe 2015 de Derechos Humanos realizado por la Comisión Ética Contra la Tortura, 2015. Disponible en: https://notascect.files.wordpress.com/2011/12/informe-2015_23-8-15.pdf.

2 Ricardo Antunes, La centralidad del trabajo hoy, Papeles de Población, 6 (25), 2000, 83-96.

3 José Luis Ugarte, Huelga y derecho, Santiago, Thomson Reuters, 2017.

${ }^{4}$ Katherine Stone, Flexibilization, globalization, and privatization: Three challenges to labour rights in our time, Osgoode Hall Law Journal, 44 (1), 77-104, 2006.

5 David Harvey, Breve historia del neoliberalismo, Madrid, Akal, 2007.

${ }^{6}$ Jurgen Habermas, Más allá del Estado nacional, Barcelona, Fondo de Cultura Económica, 1999; Joseph Stiglitz, Democratic development as the fruits of labor, 2000. Disponible en: https://www8.gsb.columbia.edu/faculty/jstiglitz/sites/jstiglitz/files/2000 Democratic Development KEYNOTE.p df.
} 
En tal escenario, ¿cuáles serían los mecanismos nacionales para garantizar de que no existan relaciones de trabajo precarias? ¿Qué se debe hacer a nivel internacional para exigir el cumplimiento a los Estados y empresas las normativas internacionales del trabajo?

\section{Nuevas formas de la clásica explotación}

Una de las industrias que ha gozado de mayor crecimiento durante las últimas décadas es la de alta tecnología. En tal ámbito la corporación Foxconn figura entre las líderes de su tipo, correspondiente al mayor fabricante de componentes electrónicos a nivel mundial. Sin embargo, ha sido objeto de diversos cuestionamientos en materia laboral. Su modelo de negocios se restringe a la fabricación de componentes electrónicos por encargo. Entre sus principales clientes figuran Apple, Amazon, Dell, Nokia, Hewlett-Packard, Motorola, Sony, Microsoft, Nintendo, entre otras grandes compañías tecnológicas de Europa, Asia y Norteamérica. Sus plantas productivas se ubican principalmente en Taiwán. Es allí donde los trabajadores y trabajadoras de la compañía han cometido incluso una serie de suicidios a modo de protesta ante las condiciones en que ejecutan sus funciones. La corporación no comercializa directamente sus productos con la masa de consumidores de dispositivos electrónicos, con lo cual evita sobreexponerse al público ${ }^{7}$, evitando así eventuales represalias comerciales.

Pero la cadena de valor de los dispositivos electrónicos ilustra no solo en la fase de manufacturación los negativos efectos del modo de producción capitalista. Dichos efectos son posibles apreciar durante los procesos de extracción de materias primas. Ejemplos clásicos en la materia se suelen ubicar a partir de las operaciones realizadas en las minas de cobalto y litio, minerales imprescindibles para el funcionamiento de los dispositivos electrónicos. Manejadas por proveedores directos e indirectos de distintas industrias de tecnología, se reconocen en dichos lugares cuestionables condiciones de explotación, humana y ambiental. Esclavitud contemporánea, trabajo infantil, desposesión de derechos de tierra y agua a las comunidades, son solo algunas de las prácticas denunciadas en la materia. Ante las demandas de activistas y diversas organizaciones, las corporaciones y Estados responden que se trata de sacrificios necesarios para el desarrollo económico y la generación de puestos de trabajo en las comunidades. Pero las contradicciones de dichos argumentos se hacen patentes a la hora de evidenciar las millonarias ganancias de las corporaciones de tecnología en el mundo.

Las denuncias de los socialistas del siglo XIX sobre la depredación del capitalismo en la humanidad y naturaleza parecen ser más vigentes que nunca. Más aún, en consideración de diferentes proyectos que incrementan el radio de acción del capital respecto de sus procesos de autovalorización. Estos ya no se centran únicamente en el trabajo, sino que también intentan superar limitaciones biológicas, geológicas y demográficas. Ejemplos de ello pueden rastrearse en diferentes procesos actualmente en curso de transformación de configuraciones geográficas del planeta. Tales son los casos de distintas iniciativas de urbanización o proyectos como el IIRSA, Plan Puebla-Panamá, y la proyección de canales interoceánicos. Todo ello tiene para el capital un único objetivo, concerniente a la aceleración del superciclo de explotación de materias primas y mano de obra para la producción y circulación de mercancías ${ }^{8}$. Diversas industrias evidencian tal situación, como lo es la textil ${ }^{9}$, donde las cadenas de suministros de corporaciones como Tommy Hilfiger, Nike, Gap, H\&M, Zara, Gucci, Louboutin, entre otras, no

\footnotetext{
${ }^{7}$ Christian Fuchs, Digital labour and Karl Marx, Londres, Routledge, 2014.

8 Martín Arboleda, La naturaleza como modo de existencia del capital: organización territorial y disolución del campesinado en el superciclo de materias primas de América Latina, Anthropologica, 35 (8), 2017, 145-176.

${ }^{9}$ Lucy Siegle, To Die For: Is Fashion Wearing Out the World? Londres, Fourth state, 2011.
} 
parece ser compatible con las condiciones en que se desempeñan los distintos actores involucrados en dicha cadena.

Junto con la modificación de las relaciones capital-naturaleza, el capital logra colonizar espacios de desarrollo de otras actividades humanas, como lo son el ocio y la recreación. Es allí donde se formula lo que ha sido definido como "trabajo digital", señalado como resultado de una creciente subsunción del trabajo por el capital, y el consecuente desdibujamiento de los esquemas tradicionales de relaciones laborales en la era contemporánea. Esto ha sido posible gracias a la masiva y acelerada introducción de dispositivos inteligentes en la cotidianidad de la población global ${ }^{10}$. De ahí que acciones aparentemente tan sencillas como navegar por Internet, googlear, interactuar por Facebook, Twitter o Instagram, constituyen el núcleo del negocio de compañías proveedoras de servicios digitales. Desde el masivo almacenamiento de información y su comercialización en industrias publicitarias, hasta el lucro derivado de cuestionables prácticas de cibervigilancia, Internet parece ser una inagotable fuente de datos -o materias primas - a ser procesados, manufacturados y puestos en circulación beneficiando a emprendedores comerciales y/o especuladores financieros.

Contrario a lo anterior, ¿cómo explicar el veloz aumento del patrimonio de compañías proveedoras de servicios digitales como Facebook, Amazon o Apple?11. Hay quienes señalan que la masiva recolección de metadatos sin información personal de usuarios puede ser positiva en variados propósitos. Por ejemplo, para la implementación de políticas públicas y sociales, como en la asignación de prestaciones, o bien en el diseño inteligente o smart de ciudades (smart cities). Sin embargo, sus detractores plantean serias interrogantes al respecto ${ }^{12}$. Además de Prism, XkeyScore, Echelon, y otros sistemas de vigilancia que se mantienen ocultos, la supresión de la privacidad en el espacio íntimo no solo es discutible desde una perspectiva liberal de derechos individuales. Ello significa igualmente un cuestionamiento que debe orientarse hacia la propiedad de los medios de almacenamiento y procesamiento masivo de datos sobre todas y cada una de las cotidianas prácticas realizadas en el mundo globalizado.

En resumen, las compañías de servicios digitales explotan a sus usuarios, obteniendo millonarias ganancias de los datos que estos les regalan a cambio de usar su plataforma digital. Ello es lo que últimamente se denomina como "trabajo digital". La condición laboral del vínculo usuario-proveedor es invisibilizada por diferentes mecanismos, y hasta el momento no se evidencian intentos por reivindicar demandas en la materia. ¿Es posible sindicalizar a los usuarios de servicios digitales para la reivindicación de sus derechos en tanto "trabajadores"? Pareciera que las condiciones no están dadas para orquestar una iniciativa de tales características. En dicho sentido, ¿se podría entonces, apelar al control obrero de la producción ${ }^{13}$, por parte de las comunidades de usuarios de servicios digitales? Difícilmente ello

10 Fuchs, op. cit., pp. 97-122.

11 Más detalles en: Vassilis Charitsis, Detlev Zwick y Alan Bradshaw, Creating Worlds that Create Audiences: Theorising Personal Data Markets in the Age of Communicative Capitalism, Triple-C, 16 (2), 2018, 820-834.

12 Ante la emergencia de las economías digitales, donde el trabajo digital constituye el eje de sus procesos de valorización, el desarrollo de medidas óptimas de participación activa en la ciudad debiera pensarse de modo más complejo. Las ciudades modernas poseen una multiplicidad de dispositivos que reciben, recopilan y transmiten datos, como cámaras de vigilancia, tarjetas de transporte, sensores biométricos en góndolas de centros comerciales, semáforos, y los mismos teléfonos inteligentes.

13 El control obrero de la producción es una alternativa que se encuentra sistematizada de manera ad-hoc a los procesos modernos de producción capitalista en las obras de Antonio Gramsci y Anton Pannekoek. Ello no significa que no haya sido trabajada previamente por pensadores de orientación socialista, comunista o anarquista. Ernest Mandel relaciona el control obrero a los consejos de fábrica y la autogestión de los trabajadores. Estas formas de contrapoder la clase constituyen alternativas al proletariado en sus procesos de arrebatamiento del control de los 
pudiera concretarse dadas las condiciones actuales de acumulación de poder y capital. Por otra parte, ¿son soluciones como la renta básica universal ${ }^{14}$ plausibles en un momento como el actual? Probablemente. Pero antes de indagar en estas alternativas, se problematizan aquellas indicadas como clásicas en la mediación de las relaciones capital-trabajo desde una perspectiva global.

\section{Problematización de la solución internacional clásica: La OIT}

Las situaciones de precariedad y explotación del trabajo por parte del capital son usualmente reivindicadas como materia de regulación jurídica. El derecho del trabajo, en dicho sentido, es en términos tradicionales caracterizado por constituir el insumo clásico de mediación en las relaciones capital-trabajo. Durante los últimos años se constata la implementación de una serie de medidas neoliberales de desregulación del trabajo, con el objetivo de incentivar la producción y el crecimiento económico. Contrario a dichas medidas, los intentos por proteger al trabajo son replicadas con permanentes amenazas de desaceleración económica, fuga de capitales, huelgas de producción, entre otros recursos del capital por mantener el trabajo a raya ${ }^{15}$. David Schweickart problematiza tal situación desde una perspectiva crítica, sosteniendo que la clase capitalista, actuando como clase-para-sí, posee un poder de fuego capaz de influir -e incluso determinar- sobre el accionar de los gobiernos.

En la constitución de un mercado mundial progresivamente integrado, los intentos por regular las relaciones capital trabajo a escala trans o inter-nacional, remiten a la Organización Internacional del Trabajo (OIT) como referente obligatorio. Dependiente de Naciones Unidas (ONU), se orienta a promover el empleo y proteger a las personas. Uno de sus principales aportes es la introducción del denominado núcleo duro del derecho del trabajo ${ }^{16}$, conformado por los derechos de a) asociación (o sindicalización), b) prohibición del trabajo forzoso y del trabajo infantil, y c) la erradicación de toda forma de discriminación por género, raza, religión o credo. Se reconoce de tal modo a las personas como portadoras de un conjunto de derechos

procesos de producción y distribución a la clase capitalista. Al mismo tiempo, plantean fórmulas que permitan lidiar con los problemas derivados del establecimiento de burocracias partidistas o de cualquier otro tipo al interior de la clase trabajadora. Revisar al respecto Antonio Gramsci, El consejo de fábrica. Publicado originalmente en L’Ordine Nouvo, el 5 de junio de 1902. Disponible en:

http://webiigg.sociales.uba.ar/empresasrecuperadas/PDF/PDF 04/consejo4.pdf;

Anton Pannekoek, Los consejos obreros, Marxist Internet Archive. Disponible en:

https://www.marxists.org/espanol/pannekoek/1940s/consejosobreros/index.htm; Ernest Mandel, Control obrero, consejos obreros, autogestión [Antología], Ciudad de México, Era, 1977. Sobre experiencias concretas de control obrero y otras formas de autogestión y colectivización laboral, con lugar en Argentina, se sugiere revisar: Gabriela Wyczykier, Sobre procesos de autogestión y recolectivización laboral en la Argentina actual, Polis, 8 (24), 2009, 197-220.

14 La noción de renta básica universal es esquematizada por Philippe Van Parijs y Yannick Vanderborght como una propuesta radical para la consolidación de una sociedad libre y una economía saludable. En pocas palabras, consiste en la elaboración de una propuesta que busque combatir la pobreza y desigualdad en el mundo actual. Los actores encargados de su implementación serían básicamente gobiernos. Las principales objeciones a la propuesta tratan del alto costo que involucraría implementar una suerte de salario mínimo universal; la desmotivación que sentirían las personas a trabajar si es que reciben un ingreso prácticamente por hacer nada; y la degeneración que ello involucraría en sectores de la población habituados al consumo de sustancias que degradan su humanidad. Más detalles en Philippe Van Parijs, Una Renta Básica para todos: asegurar la libertad real, otorgando a todos, un ingreso de subsistencia, Persona y Sociedad, 31 (2), 2017, 197-218.

15 David Schweickart, After capitalism, Oxford: Rowman and Littlefield, 2002.

16 Philip Alston, Core labour standards and the transformation of the international labour rights regime, European Journal of International Law, 15 (3), 2004, 457-521. 
básicos y universales. Idealmente, estos debiesen ser respetados, protegidos y cumplidos por todos los Estados miembro de la comunidad internacional ${ }^{17}$. Sin embargo, ello no necesariamente ocurre así.

Los lineamientos de la OIT operan en lo que se comprende como derecho internacional del trabajo. En tanto parte del derecho internacional, sus instrumentos carecen de la coercitividad necesaria para hacer respetar que estos se ejecuten en la práctica. Cada Estado está llamado a integrar instrumentos jurídicos internacionales -como convenios, tratados, acuerdos, entre otros- en sus legislaciones nacionales vigentes. Pero ello no necesariamente asegura que los Estados los integren, y menos que lo realicen del modo que les otorgue coercitividad a dichos instrumentos. Los derechos internacionales, usualmente asociados a derechos humanos, han sido criticados por las incompatibilidades que estos presuponen con los ordenamientos jurídicos locales. Dichas incompatibilidades pueden corresponder a materias de orden cultural - prácticas, sistemas de creencias, valoraciones, etc., específicas de una sociedad-, políticas - configuración de sistemas y aparatos institucionales- y económicas - procesos de valorización insertos en industrias o ramas productivas específicas-.

Por otra parte, los Estados en la inclusión de instrumentos provenientes del derecho internacional en sus jurisdicciones locales poseen el recurso de "reservas". Con este pueden restringir o modificar los términos con los que aplican internamente dispositivos jurídicos externos, dejándolos incluso en ciertos casos inoperativos. Desde un punto de vista materialista, usualmente ciertas transformaciones en niveles políticos y culturales pueden explicarse a partir de reajustes en la estructura económica. Tal argumento es especialmente relevante en consideración de la compleja configuración de una totalidad económica, en la que cada economía nacional es parte. En dicho sentido, lo mencionado sobre la competencia sostenida por los Estados por atraer inversión de capital es incompatible en muchos casos con la aplicación efectiva de normas u otras medidas orientadas a proteger el trabajo. Pese a estas limitaciones, se constatan ciertas iniciativas provenientes del mundo liberal por implementar medidas de seguridad laboral. A continuación, se revisan algunas de ellas.

\section{Tratados y acuerdos de comercio internacional}

Los efectos negativos de la globalización económica sobre el trabajo son reconocidos en todo ámbito. Y no es solo a nivel de organismos internacionales que se realizan esfuerzos en la protección del trabajo, también en diferentes cláusulas de acuerdos comerciales se incluyen elementos de regulación laboral. Dicha situación la expresan diferentes tratados comerciales, como el Tratado Comercial de América del Norte (TLCAN), y el Mercado Común del Sur ${ }^{18}$. Siguiendo lineamientos emanados desde la OIT y la Organización Mundial del Comercio (OMC), los tratados señalados exhiben una preocupación por mantener ciertos estándares sobre las condiciones de empleo y trabajo entre sus socios. En el presente documento se opta por entender tales iniciativas como desarrollos que continúan las lógicas de protección al trabajo tras la Revolución Rusa (1917) y el triunfo de la Unión Soviética ante Alemania en la Segunda Guerra Mundial (1941-1945). Tales hitos marcaron una tendencia de izquierdización en las organizaciones obreras del mundo occidental, dado lo que podría entenderse como el

\footnotetext{
17 Miguel Canessa, Los derechos humanos laborales: El núcleo duro de derechos (core rights) y el ius cogens laboral, Revista del Ministerio de Trabajo y Asuntos Sociales, 72, 2008, 111-151.

18 MERCOSUR, Tratado para la constitución de un Mercado Común entre la República Argentina, la República Federativa del Brasil, la República del Paraguay y la República Oriental del Uruguay, 1998. Disponible en: http://www.wipo.int/edocs/trtdocs/es/MERCOSUR/trt MERCOSUR.pdf.
} 
generalizado descontento de las masas obreras. Ello sería enfrentado más tarde mediante una serie de reformas por parte de los Estados de orientación liberal.

De acuerdo a lo anterior, los organismos internacionales jugaron un rol en la formulación y planificación de la implementación de distintas estrategias de lo que podría entenderse como contención revolucionaria. Tal contención se dirige principalmente a reducir las inequidades de poder y riqueza entre la clase capitalista y la clase trabajadora. Básicamente, operan como acuerdos de lo que suele denominar como conciliación de clase. Diferentes medidas como vacaciones pagadas, seguro de pre y post natalidad, seguros ante enfermedad u otros tipos de desgracias, además de concesiones de otros tipos, forman parte de los insumos que se entienden tradicionalmente como conquistas de la clase obrera. Corresponden en el fondo a políticas de cooperación y ayuda social, orientada principalmente a beneficiar a las masas empobrecidas ${ }^{19}$. Muchas de estas iniciativas fueron formuladas al interior de los organismos internacionales. Estas buscaban eludir la proliferación de experiencias de agitación política de masas, principalmente en el tercer mundo, el que pasaba a formar parte de un terreno de disputa entre las potencias liberales y socialistas del mundo post-segunda guerra mundial.

La firma del Tratado de Versalles (1919) que involucró la fundación de la OIT y, posteriormente, la Declaración de Filadelfia (1944), que actualiza y vigoriza los principios rectores de tal organización, evidencian lo señalado anteriormente. Desde un punto de vista optimista, esto puede ser entendido como avance en materia de protección de derechos sociales. También como expresión de una preocupación por proteger al trabajo de las vicisitudes del capitalismo. En las economías industrializadas ello se tradujo en la configuración de los denominados Estados de Bienestar. Ello se hizo extensivo a lo largo del siglo XX hacia las naciones subdesarrolladas. Por ejemplo, en la declaración sociolaboral de 1998 del MERCOSUR -conformado en 1991 por Argentina, Uruguay, Paraguay y Brasil- se ejemplifica dicha preocupación en una asociación comercial sudamericana. Centrada principalmente en el núcleo duro de los derechos laborales de la OIT, incentiva la creación de una comisión sociolaboral tripartita para sus países miembros. Pese a que su función se limite a la elaboración de informes de seguimiento anual sobre el cumplimiento de tales derechos, permiten la formulación de políticas sectoriales que operen en la materia ${ }^{20}$.

Por otra parte, el TLCAN -compuesto por México, Canadá y Estados Unidos-ratificó el denominado Acuerdo para la Cooperación Laboral en América del Norte (ACLAN). Tal acuerdo ha sido diseñado para tratar problemas concernientes, principalmente, en materias laborales. Consistente en los denominados "once principios norteamericanos del trabajo" posee dos objetivos clave: i) mejorar condiciones laborales y estándares de vida; ii) y promover y reforzar efectivamente dichas condiciones y estándares. Mediante la creación de las Oficinas de Administración Nacional (OAN), permite a diferentes agrupaciones movilizar sus reivindicaciones en pro de estandarizar condiciones de empleo y trabajo bajo los términos que el TLCAN establece ${ }^{21}$. Pese a no poseer coercitividad jurídica, sí posee la facultad de sancionar a distintos agentes (sean corporativos o estatales) que no cumplan con los estándares comprometidos. Ello involucra la constitución de un complejo entramado institucional de agentes públicos y privados. Entre ellos destacan agentes ministeriales del mundo del trabajo

\footnotetext{
19 Sergio Grez, Un episodio de las políticas del "Tercer Período" de la Internacional Comunista: elecciones presidenciales en Chile, 1931, Historia, 48 (2), 2015, 465-503.

20 Mercosur, op., cit., 1998.

21 Tamara Kay, Labor transnationalism and global governance: The impact of NAFTA on transnational labor relationships in North America, American journal of sociology, 111 (3), 2005, 715-756.
} 
de las tres naciones miembros, además de paneles arbitrales escogidos consensuadamente por estos. De ahí que la resolución de diferentes disputas pueda ser canalizada por diferentes medios o vías, acorde a sus características.

Ahora bien, ambas iniciativas han recibido múltiples críticas dada sus deficitarias implementaciones. Traslucen, en dicho sentido, una serie de contradicciones en la mitigación que realizan sobre las asimetrías capital-trabajo. Al funcionar sobre una escala transnacional, en primer lugar, encuentran diferentes resistencias a sus modos de operación. En el caso de la implementación de las cláusulas laborales del TLCAN, tales resistencias provienen desde el mundo privado ${ }^{22}$. Ante ellas se erigen diferentes iniciativas, como agrupaciones activistas pro defensa de los derechos laborales. De ahí se originan disputas que deben lidiar con la complejidad propia de disputas jurídicas del ámbito del trabajo, en las que intervienen agentes públicos (tribunales, parlamentarios, entre otros), privados (empresas y sus respectivos estudios jurídicos) y trabajadores (sindicalizados o no). Por tanto, ¿constituyen iniciativas como estas una protección real del trabajo? Al parecer, y en vista de las vicisitudes de su implementación, pareciera ser que estas deberían ser complementadas con otras estrategias de protección, ya que en la práctica evidencian signos de estancamiento y/o desgaste dada su alta reglamentación.

\section{Los acuerdos políticos internacionales}

A las cláusulas laborales incluidas en tratados y acuerdos de comercio internacional se suman también cláusulas laborales presentes en diferentes asociaciones internacionales de carácter estatal. En el marco de la presente revisión, se exploran en dicho sentido ciertos aspectos en la materia de la Unión Europea (UE) y la Organización Para la Cooperación y el Desarrollo Económico (OCDE) ${ }^{23}$. Usualmente se caracteriza a la UE por evidenciar mayores avances en materia de integración jurídica y legislativa entre sus Estados miembros. No obstante, debe enfrentar ciertas limitaciones comunes a cualquier conglomerado de actores nacionales-estatales. En lo concerniente a la estandarización de las condiciones de empleo y trabajo, la implementación de los derechos laborales está supeditada a las legislaciones de los países miembros. Como estas poseen niveles de heterogeneidad expresados en diferentes asuntos - como salariales, de sindicación, negociación colectiva, protección a la natalidad, o de previsión social- es que se distinguen ciertas voces que llaman a estandarizar dichos elementos ${ }^{24}$.

El piso sería trazado a partir de las jurisdicciones de los países que poseen los mayores avances en la materia, como lo son aquellos del norte de Europa -básicamente, Noruega, Suecia, Finlandia y Dinamarca-. Es lo que busca precisamente la Confederación Europea de Sindicatos (CES). Tal organización intentó movilizar la adopción de una "carta comunitaria de derechos sociales", la cual se orientaría a resguardar efectivamente derechos de negociación colectiva, libertad de asociación, y libertad de movilización para los habitantes de los países

\footnotetext{
22 Tamara Kay, y Rhonda Evans, Trade Battles: Activism and the Politicization of International Trade Policy, Oxford University Press, 2018.

23 OCDE, International trade and core labour standards, 2000. Disponible en: https://www.oecd.org/tad/1917944.pdf; OCDE, Directrices de la OCDE sobre el Gobierno Corporativo de las Empresas Públicas, 2011. Disponible en:

https://www.oecd.org/daf/ca/corporategovernanceofstate-ownedenterprises/48632643.pdf.

24 Paul Teague, Standard-setting for labour in regional trading blocs: The EU and NAFTA compared, Journal of Public Policy, 22 (3), 2002, 325-348.
} 
miembro de la Unión. No obstante, sus detractores apelan a la heterogeneidad económica, política y cultural en la inviabilidad de la propuesta. Pese a los avances de integración de la UE, prevalece una fuerte variabilidad de desarrollo económico y político entre sus países miembros. Allí es posible encontrar países que poseen altos índices de desarrollo humano como Noruega, y otros con niveles similares a los países como Chile, tal como el caso de algunos países de Europa del Este: Hungría, Croacia o Rumania.

En el caso de la OCDE, la tarea de proteger los derechos laborales se reconoce como responsabilidad de la OIT. Ello no exime a la OCDE de elaborar informes en el que se indiquen aspectos propios de las condiciones de empleo y trabajo que se encuentran entre sus países miembro. Por ejemplo, en el año 2000 se indicó que solo 9 de sus 30 miembros han ratificado convenios correspondientes al núcleo duro de los derechos del trabajo ${ }^{25}$. Pese a que no se hicieron futuros informes similares, sí se habló en dicha oportunidad de la existencia de huecos sustanciales entre ratificación y aplicación efectiva de tal tipo de derechos. El informe intenta replicar la lectura de que el aumento de los estándares en las condiciones de empleo y trabajo es negativo para el libre funcionamiento de los mercados. Tal informe en defensa de la estandarización ascendente de mínimos laborales fue elaborado por Joseph Stiglitz. En tanto nobel de economía y militante intelectual del Estado benefactor y la socialdemocracia, su hipótesis aboga por la mejora de las condiciones laborales al interior de las economías nacionales.

Stiglitz indica que mejorar las condiciones de trabajo en los diferentes países promueve la llegada de mano de obra calificada. Esto se traduciría, de acuerdo a Stiglitz, en el incremento de los niveles de eficiencia y productividad de las distintas ramas productivas presentes en un país ${ }^{26}$. Sin embargo, iniciativas como estas no pueden traducirse directamente en soluciones concretas a la precarización del trabajo en el capitalismo avanzado. Por el contrario, lo señalado por Stiglitz podría tender al aumento de inequidades sociales y económicas entre países desarrollados y subdesarrollados. Ante ello sería necesario implementar medidas que operen con una perspectiva global, por sobre fundadas en nacionalismos metodológicos. En vista de los avances de las dinámicas propias de acumulación a escala global, se requiere de avanzar en formulaciones que combatan efectivamente la fragmentación de la clase trabajadora mundial. Esto podría significar un avance en materia de reducir la creciente precarización del trabajo. Dicho proceso involucra al mismo tiempo una acelerada transformación de la mano de obra global, orientada a su proletarización por sobre "campesinización"27.

Por tanto, iniciativas como las sostenidas por la UE y OCDE en el fondo distan de convertirse en estrategias reales de mejora de condiciones de trabajo. Por sobre limitar los efectos de la subsunción del proceso de trabajo, lo adaptan a los procesos de valorización de este por parte del capital. Así lo expresan finalmente diferentes proyectos políticos de "mitigación del descontento" propio de las clases trabajadoras, desarrollados tanto por gobiernos como por corporaciones. Estas últimas reflejan tal lineamiento en la materialización de diferentes estrategias de Responsabilidad Social Empresarial (RSE). Asimismo, la conformación de iniciativas globales en el mundo del trabajo, o de la organización obrera, ha sido referido tradicionalmente como internacionalismo. Pareciera ser que hoy más que nunca se necesita de la revitalización de las internacionales ante el implacable avance del capital transnacional. Más aún, considerando los efectos de las crisis mundiales en la producción capitalista se dejan sentir con fuerza sobre unidades territoriales cada vez más aleatorias que

25 OCDE, op. cit., pp. 22-30, 2000.

26 Stiglitz, op. cit., 31-37, 2000.

27 Arboleda, op. cit., 168-169. 
sobredeterminadas ${ }^{28}$. Pese a estas constataciones, el capital ha restringido al trabajo en la continuación del anclaje nacionalista metodológico en el desarrollo de sus tácticas de reivindicación de sus derechos, cuestión abordada en el siguiente apartado.

\section{Limitaciones nacionales a la protección del trabajo}

La lucha de clases en su formulación marxiana remite a los enfrentamientos que, durante los diferentes períodos históricos, con sus respectivos modos de producción, han protagonizado las clases dominantes y dominadas. Para Karl Marx en el Manifiesto Comunista 29 esboza la lucha de clases propia de la era moderna, y del modo de producción capitalista, entre burgueses y proletarios. La lucha de clases será para Marx la articulación de todas las disputas que desarrollarán las clases trabajadoras en sus espacios locales, gracias a los desarrollos técnicos de la comunicación. El escalamiento de la lucha de clases desde un espacio local a uno global es representado por León Trotsky ${ }^{30}$, siguiendo a Vladimir Illich Lenin, como una revolución social de orden mundial. En consideración de la hipótesis del desarrollo desigual y combinado, que es profundizado más tarde por las teorías de la dependencia, Trotsky traza los lineamientos seguidos por el capital en la constitución de un mercado mundial. Tal mercado mundial se caracteriza por el desarrollo global de las fuerzas productivas y de una división mundial del trabajo entre países "maduros" (o desarrollados) e "inmaduros" (o subdesarrollados). Dicho esquema es el que se señala hoy en día como economía globalizada o globalización económica.

Pero la constitución del ordenamiento jurídico global se basa en la articulación de jurisdicciones nacionales. Cada jurisdicción posee una configuración particular que le otorga una especificidad y complejidad propia. En un primer momento, ello limita la articulación de una lucha de clases erigida por la clase trabajadora mundial. Más aún, en un segundo momento, y pese a los avances técnicos contemporáneos de la comunicación, tal lucha de clases mundial debe lidiar con las particularidades económicas y culturales de los diferentes conglomerados obreros y campesinos del globo. Tal situación, prevista por Trotsky, constituye uno de los ejes de su teoría de la revolución permanente. Desde la perspectiva trotskista clásica, la revolución puede adquirir una orientación política o "democrática" - vale decir, sujeta a los parámetros institucionales establecidos por la burguesía nacional-y social o "socialista". El éxito de las revoluciones, sean democráticas o socialistas, dependerá del desarrollo de una revolución socialista internacional. Para Trotsky dicho camino es el único que permitirá lidiar con los incidentes ocasionados por las burguesías nacionales e internacionales.

La soberanía nacional de tal modo es entendida desde una perspectiva crítica como bastión del ordenamiento jurídico propio de las burguesías locales. En el caso latinoamericano, no es de extrañar que hayan sido las proto burguesías nacionales - por sobre las masas obreras y campesinas- las interesadas en independizar las colonias del orden aristocrático-clerical. En el caso de las colonias sudamericanas de habla hispana, tal es el proyecto liderado por Simón Bolívar y José de San Martín, guiados por principios democrático liberales, lograron desarrollar una serie de revoluciones políticas que alcanzaron a articularse como una guerra internacionalista integrada contra el dominio español. De su resultado se mantienen vigentes hasta el día de hoy las naciones sudamericanas en tanto Estados nacionales libres y soberanos.

\footnotetext{
${ }^{28}$ Louis Althusser, Para un materialismo aleatorio, Madrid, Arena, 2002; y Louis Althusser, La revolución teórica de Marx, México D.F., Siglo XXI, 1967.

${ }^{29}$ Karl Marx y Friedrich Engels, El manifiesto comunista, Buenos Aires, Taurus, 2017.

${ }^{30}$ León Trotsky, La revolución permanente, Isla de Maipo, Askasis, 2016.
} 
Así, la burguesía asume que su articulación internacional en tanto clase-para-sí ${ }^{31}$ posibilitará sentar las bases para su dominio. Debe entonces la burguesía generar un ordenamiento que sea capaz de limitar la articulación internacional del agente de clase que, una vez neutralizada la aristocracia, constituye su futura amenaza: las clases trabajadoras.

El derecho del trabajo supedita la negociación de las condiciones de empleo y trabajo a los espacios nacionales. El derecho laboral, en tanto encargado de mediar las relaciones capitaltrabajo, opera limitado bajo el ordenamiento jurídico instaurado por las revoluciones burguesas a escala global. Ello contribuye a la desarticulación de las luchas obreras internacionalistas. Quedan de tal modo las clases trabajadoras de los diferentes países enfrascadas en luchas sujetas a sus particularidades políticas, económicas, culturales, históricas, jurídicas y sociales. Pese a sus intentos de escalar, sus disputas en principios o fundamentos jurídicos de derechos humanos, ello no ha tenido éxito. Dadas las restricciones coercitivas del ius cogens, las clases trabajadoras nacionales pueden al menos acudir al potencial político del mismo. Los instrumentos basados en lineamientos universales de derechos humanos usualmente se materializan en tratados o acuerdos internacionales. Sobre estos tratados los Estados adoptan medidas y estrategias comunes sobre materias específicas ${ }^{32}$. No obstante, los acuerdos internacionales se encuentran limitados en la práctica debido a recursos como las reservas.

El potencial político de medidas fundadas en fórmulas de derechos humanos o universales descansa en la realización de sanciones aplicables sobre los Estados. Dichas sanciones pueden hacerse efectivas una vez que se constate que los Estados no cumplen con los términos de convenios a los cuales estos han adherido. En materia laboral son organizaciones de carácter sindical las que por ejemplo pueden invocar tales recursos jurídicos internacionales para su incumplimiento por parte de un Estado particular. El procedimiento para ejecutar una acción de estas características se encuentra normado de acuerdo a la instancia donde esta se ejecute. Instancias para dichos propósitos son por ejemplo los tribunales internacionales de la Corte Interamericana de Derechos Humanos. En dicho sentido, una demanda en caso de ser acogida y conducida hasta sus últimas consecuencias, puede traducirse en la ejecución de sanciones económicas desde la Comunidad Internacional hacia el Estado en cuestión ${ }^{33}$.

\footnotetext{
31 El concepto de clase-para-sí posee un amplio abordaje al interior de la tradición marxista, y debe entenderse como parte de la construcción teórica y analítica de clases y lucha de clases en Marx. Al respecto se sugiere revisar Inés Izaguirre, Acerca de la teoría de las clases y de la lucha de clases. Por qué han sido sustituidas las clases sociales en el discurso académico, Theomai, 29, 13-37, año.

32 Claudio Nash, Derecho internacional de los derechos humanos en Chile. Recepción y aplicación en el ámbito interno, Centro de Derechos Humanos, Universidad de Chile, 2012. Disponible en:

http://repositorio.uchile.cl/bitstream/handle/2250/142503/Derecho-internacional-de-los-derechos-humanosen-Chile.pdf?sequence $=1$.

33 A las limitaciones jurídicas deben agregarse las diferentes tácticas y estrategias con las que el capital intenta mermar el intento de la clase trabajadora por hacer respetar sus derechos laborales. Entre estos recursos del empresariado se encuentran las técnicas lobby y la manipulación mediática. El lobby se refiere a la ejecución de influencias por parte de ciertos grupos de poder sobre diferentes organizaciones involucradas en materias laborales. Potenciales víctimas de la persuasión lobbysta son por ejemplo líderes sindicales corruptibles. Más información en Sebastián Salvia, Alianzas de los empresarios industriales en la crisis del neoliberalismo en Argentina, Revista de sociologia e política, 25 (62), 2017, 93-113. Sobre la manipulación mediática por su parte puede ser ejecutada con el objetivo de difamar reivindicaciones laborales por diferentes motivos. Ejemplos de ello pueden encontrarse en las reivindicaciones chilenas por el cambio al sistema de pensiones. Esta situación es facilitada por la concentración de los medios de comunicación en pocas manos, familiarizadas con grupos de poder empresarial. Sobre este último punto se sugiere revisar Rocío Knipp, Jorge Valdebenito y Andrés Barriga, No basta con Twittear. \#NoMásAFP ante el sistema de pensiones en Chile, Revista Hipertextos, 9 (6), 148-184, 2018.
} 


\section{La regulación del trabajo en Chile}

Existen diferentes lecturas o interpretaciones sobre la regulación del trabajo en Chile, así como de sus fuentes u orígenes. Estos últimos son usualmente referidos en las luchas obreras del siglo XIX y comienzos del siglo XX. La materialización de una serie de conquistas laborales se encuentra en el primer Código Laboral que data de 1931. Diferentes historiadores como Gabriel Salazar, Julio Pinto, Sergio Grez, entre otros, han producido notables trabajos que detallan dicho proceso. No obstante, en el marco del presente documento se adhiere a la interpretación que las conquistas laborales de comienzos del siglo XX responden a las luchas obreras - de orientaciones socialistas, comunistas y anarquistas- combinadas con medidas de contención revolucionaria - de orientación liberal y socialdemócrata-. De tal modo, es posible caracterizar el proceso de 1931 a 1970 como una seguidilla dialéctica de avances y retrocesos de las luchas laborales en Chile, con un notorio avance de estas durante el gobierno de la Unidad Popular.

No obstante, ello finalizó una vez ocurrido el golpe de Estado de 1973 con la consecuente implementación de medidas de neoliberalización económica en el país. Estas han significado un rotundo avance del capital sobre el trabajo, fijando las correlaciones de fuerzas en Chile equilibradas hacia el empresariado. En dicho sentido, la contra-reforma agraria ${ }^{34}$ destaca en tanto plan de expropiación de recursos naturales. Esta beneficiaría exclusivamente a la clase terrateniente chilena, constituyendo uno de los hitos fundacionales del modelo económico y social implementado tras el golpe de Estado de 1973. De ahí que la consolidación de un modelo de producción de carácter extractivista ${ }^{35}$ se realice en correlato con que David Harvey ha denominado expresión de procesos de acumulación por desposesión ${ }^{36}$. Dicha matriz contribuye a la agudización de contradicciones en precariedad laboral, destrucción medioambiental, y reestructuración cultural de clases sociales ${ }^{37}$. En paralelo, se han puesto en marcha sofisticadas formas jurídicas implementadas con objeto de desmovilizar políticamente la población chilena.

Una de tales medidas jurídicas de desmovilización corresponde a la aparatosa reglamentación de la huelga en Chile. La huelga se entiende clásicamente como insumo tradicional del trabajo en su lucha contra el capital. Consiste en la paralización de las actividades productivas en una determinada fábrica o empresa. Su realización presupone una medida de presión por parte de los trabajadores hacia el empresariado para la consecución de un determinado fin, usualmente una mejora de condiciones de empleo o trabajo. En Chile la reglamentación, instaurada vía jurídica sobre la huelga, la ha restringido únicamente bajo

\footnotetext{
34 Nicholas Widmyer, El pueblo aquí está totalmente humillado. La Contrarreforma Agraria en Chile, Repositorio del Museo de la memoria y los derechos humanos, 2015. Disponible en: http://www.cedocmuseodelamemoria.cl/wpcontent/uploads/2015/12/Nicholas-Widmyer.pdf.

35 Eduardo Gudynas, Extractivismos: ecología, economía y política de un modo de entender el desarrollo y la naturaleza, Cochabamba, CEDIB, 2015.

36 David Harvey, El nuevo imperialismo: acumulación por desposesión, Buenos Aires, CLACSO, 2005. Disponible en: http://www.biblioteca.clacso.edu.ar/gsdl/collect/clacso/index/assoc/D8555.dir/harvey.pdf.

37 Sobre la descripción de la precariedad laboral en cuanto concepto y su escalamiento a la conformación de una nueva clase social, se sugiere revisar Guy Standing, The Precariat: From Denizens to Citizens?, Polity, 44 (4), 2012, 588-608. Sobre la destrucción medioambiental ocasionada por el modo de producción industrial, y algunas reflexiones sobre su resolución, se invita a profundizar a la discusión a partir del texto Michael Löwy, Ecosocialismo. La alternativa radical a la catástrofe ecológica capitalista, Buenos Aires, Ediciones Herramienta y Editorial El Colectivo, 2011. Acerca de la configuración de nuevas identidades conforma al desarrollo de nuevas formas de producción económica en el contexto chileno se recomienda comenzar la discusión por Tomás Moulian, Chile actual. Anatomía de un mito, Santiago de Chile, ARCIS y LOM, 1998.
} 
contextos de negociación colectiva ${ }^{38}$. Ello puede entenderse como parte de una estrategia orientada a obstaculizar su desarrollo. De tal modo, las huelgas desarrolladas fuera de un proceso de negociación colectiva pasan a ser ilegales o "extralegales"39. La tasa de conflictividad en Chile varía de acuerdo a ramas productivas (figura 1). De acuerdo a datos entregados por el Observatorio de Huelgas Laborales ${ }^{40}$, las áreas con mayores índices de movilizaciones o huelgas "extralegales" se encuentran en las siguientes áreas: agricultura y pesca (85\%), transporte y almacenamiento $(52,9 \%)$, minería $(54,5 \%)^{41}$.

\section{Gráfico 6: Número de huelgas por rama de actividad económica y legalidad en el sector privado (2017)}

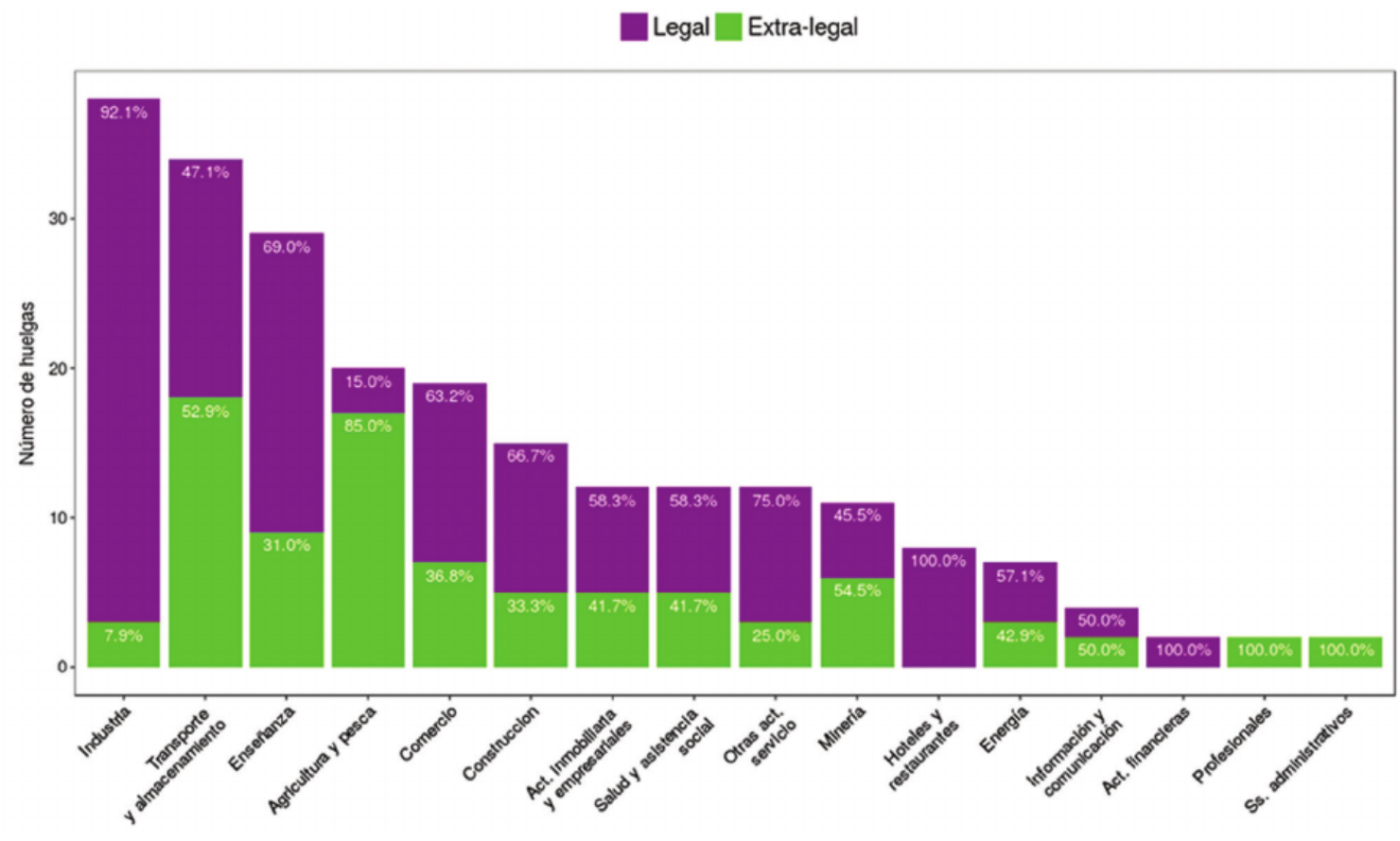

Figura 1.

Fuente: OHL, Informe de Huelgas Laborales 2017, 2018, pp. 16

A lo anterior debe sumarse la consideración concerniente a que una negociación colectiva debe realizarse entre un sindicato y empresa. Y precisamente, la conformación de sindicatos en Chile ha sido otro elemento que ha intentado desmontar la regulación laboral neoliberal ${ }^{42}$. Hoy en día, la tasa de sindicalización de la fuerza laboral en Chile es cercana al 14\% (figura 2). Tal cifra se entiende como parte de un plan orientado a des-sindicalizar a la fuerza laboral chilena, desarrollado desde la dictadura de Augusto Pinochet. La siguiente figura ilustra

\footnotetext{
38 José Luis Ugarte, Huelga y derecho, Santiago, Thomson Reuters, 2017.

39 Ugarte, op. cit., 2017.

40 OHL, Informe Huelgas Laborales en Chile 2017, 2018. Disponible en: http://www.observatoriodehuelgas.cl.

${ }^{41}$ Entre ellas deben añadirse huelgas de los sectores profesionales y administrativos, ambos con un $100 \%$ de huelgas extralegales.

42 OIT, La negociación colectiva: un principio fundamental, un derecho, un convenio, 1999. Disponible en: https://www.ilo.org/wcmsp5/groups/public/---ed dialogue/---actrav/documents/publication/wcms 116092.pdf
} 
la evolución histórica de la tasa de sindicalización en Chile entre el año 1960 y 2013. Las estimaciones sobre las cifras actuales (2018) indican que la tasa de sindicalización estaría cercana al 11\%. Esto sería resultado de los efectos de las políticas de flexibilización laboral. Estas últimas han configurado un escenario laboral caracterizado por formas de empleo precario, como lo son el subcontrato y diferentes formas de trabajo informal -como el "cuentapropismo"-.

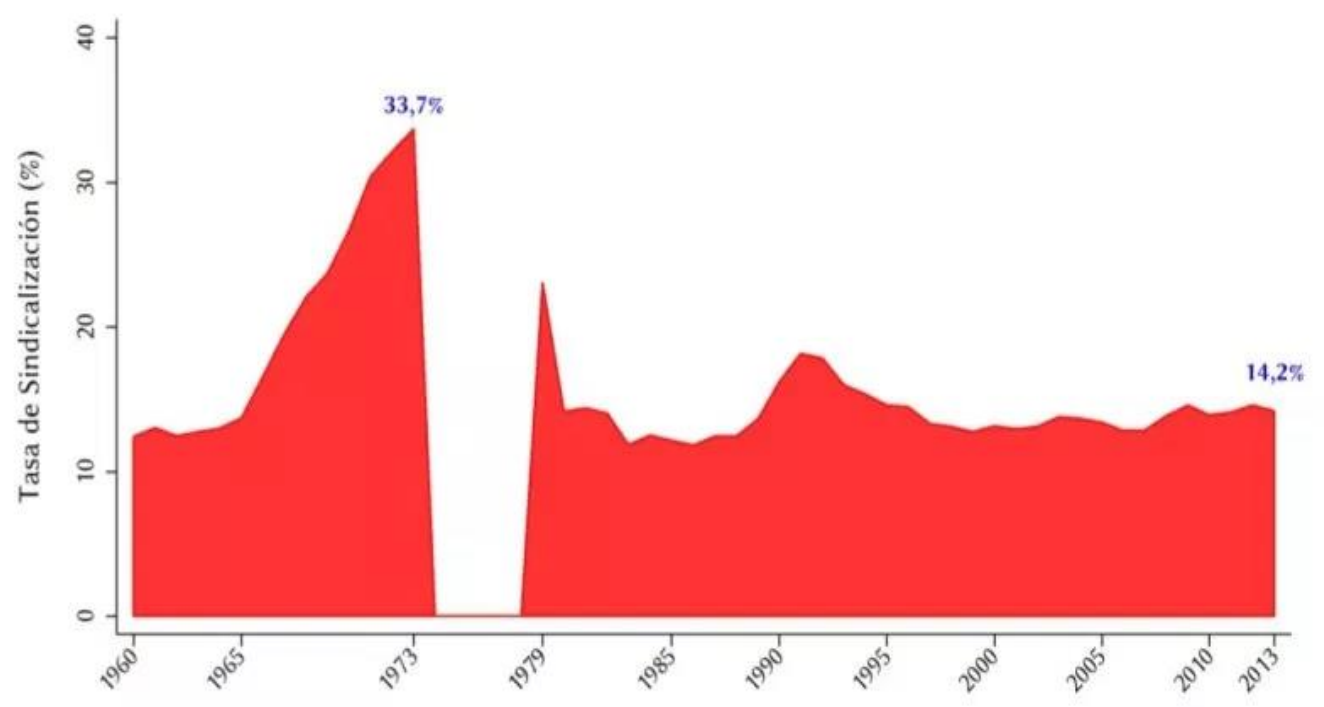

Fuente: Fundación SOL, en base a Estadisticas Sindicales 1956 -1972 DERTO. Campero y Valenzuela (1984), Frias, P (2002) y Anuario DT Nota: Se ha censurado el periodo 1974-1979 por tratarse de un lapso donde la Negociación Colectiva estuvo prohibida por Ley

Figura 2. [Fuente descrita en la imagen].

Pareciera ser que ante un escenario como el actual no hay muchas alternativas de acción para la protección del trabajo ante el avance del capital. En primer lugar, la huelga ha sido hiperreglamentada - como señala un informe de la OIT43-, y en segundo lugar, la tasa de sindicalización evidencia signos de sostenido descenso. La clásica pregunta retórica de Lenin sobre ¿qué hacer? se mantiene aún vigente. De acuerdo a Aldo Mascareño ${ }^{44}$, quien sigue a Niklas Luhmann, la regulación jurídica materializa la coordinación de las respectivas expectativas normativas de los actores involucrados en un determinado ámbito de acción. De manera general esto ha sido indicado como el carácter tripartito, o intersectorial, de las negociaciones ${ }^{45}$. No obstante, tal alusión no debe conducir a confusiones. En Chile la negociación tripartita evidencia un escaso desarrollo. Esto se debe a que la negociación colectiva se encuentra centrada a nivel de empresa. Al interior de estas, puede darse incluso la situación en que debido a la existencia de múltiples sindicatos la negociación colectiva no se realice entre "empresa" y "trabajadores" como un colectivo, sino estos últimos fragmentados en pequeños grupos o cuadrillas.

\footnotetext{
43 OIT, op., cit. 1999.

${ }_{44}$ Aldo Mascareño, Regímenes jurídicos en la constitución de la sociedad mundial, Política criminal, 2, 2007, 1-39.

45 OIT, Diálogo social tripartito de ámbito nacional. Una guía de la OIT para una mejor gobernanza, 2017; en: https://bit.ly/2RuigS9
} 
Esto se traduce en una escasa cobertura de trabajadores por instrumentos colectivos. Esto ha sido ampliamente criticado por diferentes sectores abocados al estudio de la doctrina laboral chilena ${ }^{46}$. Pese a ello, hasta el momento, la expectativa de negociar colectivamente condiciones de empleo y trabajo por rama, por sobre empresa, dista de ser una realidad. En dicho sentido, y aludiendo a la afirmación de Mascareño, ¿las expectativas de cuál actor se están materializando en los términos que delimita el derecho para la negociación de condiciones de empleo y trabajo en Chile? Tentativamente, y bajo el esquema de relaciones laborales actual, la conceptualización de Mascareño pareciera referirse a un estadio de correlaciones de fuerzas pretérito -o nunca existente- en un país como Chile.

La huelga en el momento actual constituye una materia de reivindicación laboral de alta relevancia, no solo en Chile, sino el resto del denominado "mundo libre". No obstante, medidas como estas pueden ser contestadas mediante diferentes tácticas por parte del capital. Por ejemplo, a la deslocalización productiva se suma la apertura de plantas productivas en aguas internacionales. Pero aun así diferentes actividades como extracción de materias primas y comercialización de mercancías deben realizarse donde habite el grueso de la población, vale decir, países. Al mismo tiempo, tales actividades requieren de mano de obra, la cual se encontraría protegida por las reglamentaciones laborales de los respectivos países en que estas se desarrollen. Quedaría entonces acudir a salidas aún más extremas, como lo es la automatización -y robotización-47, la cual consiste en el paulatino reemplazo de humanos por máquinas. Apuestas como las de Van Parijs de la renta básica universal parten de supuestos como el de una sociedad con actividades extractivas, productivas, y comerciales altamente automatizadas.

Para Marx el problema de la economía política residía en quién se adueña y distribuye el excedente de la producción. En dicho sentido, el control obrero de la producción, como lo formulaba Anton Pannekoek, adquiere relevancia política y económica. Dicha relevancia es aún mayor si se consideran las crecientes condiciones de acumulación y desigualdad de poder y riqueza que evidencian los diferentes indicadores internacionales, incluso los más conservadores. El control obrero se entiende como un punto medio, de carácter transicional, entre la huelga y la sociedad socialista. Socialismo, en dicho sentido, remite a la socialización de los medios de producción, mediante diferentes formas o aparatos organizacionales o institucionales. El socialismo se entiende al mismo tiempo como transición al comunismo, estadio donde la propiedad privada y la sociedad de clases ya han sido abolidas. No obstante, las experiencias que evidencian la dirección de las acciones organizadas de la clase trabajadora hacia la consecución del control obrero no necesariamente desembocan en la construcción del socialismo, y menos del comunismo. Estas en muchos casos se han visto imbricadas bajo dinámicas propias de la producción y comercialización capitalista, como lo es el caso de Zanon.

Sin embargo, de todos modos, allí diferentes cuestiones relacionadas a la organización del trabajo y de los procesos productivos son ajustadas exclusivamente siguiendo los lineamientos de la organización obrera. Reemplaza por ende las determinaciones patronales

\footnotetext{
$46 \mathrm{Al}$ respecto revisar Sergio Gamonal, Fundamentos de derecho laboral. Santiago de Chile, LexisNexis, 2008; Rodrigo Palomo, La organización sindical en Chile. XX Jornadas Nacionales de Derecho del Trabajo y la Seguridad Social, Santiago de Chile, Librotecnia, 2014; y José Ugarte, Huelga y derecho, Santiago, Thomson Reuters, 2017.

47 La automatización ha significado el desarrollo de un debate en materia jurídica laboral en Chile, especialmente, debido al reemplazo de trabajadores por máquinas durante procesos de huelga. Para introducir en el debate se sugiere revisar el siguiente texto y nota de prensa: Francisco Pérez, El conflicto laboral en la actualidad: Los nuevos conflictos, Ius et praxis, 16 (1), 2010, 441-452; Pulso, DT zanja discusión y declara ilegal la automatización para reemplazo en huelga, 2018. Disponible en: Http://www.pulso.cl/economia-dinero/dt-zanja-discusion-declarailegal-la-automatizacion-reemplazo-huelga/.
} 
por decisiones colectivas. Constituye de tal modo, un lineamiento de lucha por sobre una reivindicación a realizarse bajo los parámetros delimitados por las jurisdicciones vigentes. Se trata de un contra-despojo con interés de clase por hacerse con la propiedad solidaria de los medios de producción. Ahora bien, en el período actual, caracterizado por correlaciones de fuerzas particulares, en un país como Chile, hablar de control parece utópico. No obstante, si se consideran por ejemplo la seguidilla de desastres ambientales, cuya responsabilidad se encuentra distribuida entre corporaciones y agentes gubernamentales, hablar de control obrero de la producción no parece algo utópico.

A propósito de ciertos desastres ambientales propios de las zonas de sacrificio en Chile, como lo es la bahía de Quintero-Puchuncaví, ciertas voces se han alzado solicitando nacionalización de la producción. Sobre esta última, se podría aplicar una planificación de control obrero, a modo de eludir las viejas prácticas de lobby y conflictos de intereses propios de la gestión del Estado en el período actual. Por ejemplo, si se considera que precisamente en empresas del Estado, como lo es Codelco, se reproducen prácticas de explotación precaria del trabajo como lo es el subcontrato, una reivindicación radical como esta adquiere mayor relevancia. 0 incluso, si no se pierde de vista que precisamente en empresas como Codelco, una vez que sus trabajadores subcontratados se han movilizado buscando mejoras en sus condiciones de empleo y trabajo, a algunos de ellos se les ha dado muerte, como sucedió con Nelson Quichillao en el año $2015^{48}$.

\section{Reflexiones finales}

La creciente precarización de los regímenes de trabajo y la extensión global de estos, llama a la identificación de alternativas viables para su combate. La reivindicación de los derechos laborales constituye hoy en día una especie de punta de lanza en las disputas por mejorar las condiciones de empleo y trabajo en la actualidad. No obstante, el capital ha evidenciado una alta capacidad de eludir, e incluso menoscabar, la efectividad de los derechos del trabajo. Tal punto debe ser analizado desde un punto de vista crítico. Karl Marx a lo largo de su obra mantuvo una relación no lineal respecto al derecho. Por ejemplo, en La ideología alemana, junto a Engels, mantienen su oposición inequívoca a la ley. Ello cambia en El Capital, donde elogia la consagración por ley de la jornada laboral de diez horas como una conquista de la clase trabajadora. A su vez, en El manifiesto comunista Marx y Engels reducen el Estado a una instancia instrumental para manejar los asuntos de la clase dominante.

Paul O'Connell ${ }^{49}$, sistematizando las críticas marxistas del derecho, a partir de autores como Pashukanis, Renner, Althusser, Poulantzas, y E.P. Thompson, señala un camino sugerente para los términos de la presente discusión. El punto clave de su argumento es el reconocimiento de la ausencia de una teoría unificada del Estado, del derecho o de las leyes en la tradición marxista. Siguiendo los trabajos de Georg Lukács y de Cyril James, indica el único aspecto que permite tratar con el marxismo es la cuestión del método. Así, los análisis del derecho, de las leyes, y de los Estados deben seguir los lineamientos del materialismo dialéctico, reconociendo la centralidad de la lucha de clases, y la transitoriedad del modo de producción capitalista. Con dichos elementos, el análisis específico de los aspectos laborales presentes en convenios internacionales de la OIT, OCDE, TLCAN, UE, MERCOSUR, conducirá a determinar sus funciones

48 CECT, Chile: Derechos humanos o barbarie. Informe 2015 de Derechos Humanos realizado por la Comisión Ética Contra la Tortura, 2015, 14-21.

${ }^{49}$ Paul O'Connell, Law, Marxism and Method, Triple-C, 16 (2), 2018, 647-655. 
ideológicas ${ }^{50}$ y económicas ${ }^{51}$. Así, de la constatación de que el derecho contribuye al mantenimiento de las bases necesarias para el sostenimiento del orden liberal -o burguéspodría el análisis específico del fenómeno jurídico conducir a sus posibilidades de superación.

Sobre tales posibilidades de superación del orden vigente se han trazado tres alternativas: defensa de la huelga, renta básica universal y control obrero de la producción. Las tres alternativas bajo los ordenamientos jurídicos vigentes están sujetas a limitaciones que no permiten su viabilidad táctica en el actual período. Probablemente el análisis político y de coyuntura indicará que tampoco se encuentran las condiciones políticas y/o sociales para su reivindicación. Pensando en el momento y escenario actual de un país como Chile, intentos como la conformación de la Central Clasista de Trabajadores ${ }^{52}$ constituyen un buen augurio en la movilización de reivindicaciones radicales hacia la defensa del trabajo. De ahí podrían adelantarse condiciones para el posicionamiento de la discusión respecto a las alternativas esbozadas de mitigación del avance del capital, y de la creciente precarización del trabajo. De momento, el presente documento intenta exponer contenidos básicos para la discusión y acción orientada a la defensa de la clase trabajadora en el mundo actual.

\section{Referencias bibliográficas}

Aguilar, Omar, “Globalización, modelo de desarrollo y trabajo en Chile”, Némesis, 4, 2004.

Alston, Philip, "Core labour standards and the transformation of the international labour rights regime", European Journal of International Law, 15 (3), 2004, 457-521.

Althusser, Louis, La revolución teórica de Marx, México D.F., Siglo XXI, 1967.

Althusser, Louis, Para un materialismo aleatorio, Madrid, Arena, 2002.

Antunes, Ricardo, "La centralidad del trabajo hoy", Papeles de Población, 6 (25), 2000, 83-96.

Arboleda, Martín, "La naturaleza como modo de existencia del capital: organización territorial y disolución del campesinado en el superciclo de materias primas de América Latina”, Anthropologica, 35 (8), 2017, 145-176.

Canessa, Miguel, "Los derechos humanos laborales: El núcleo duro de derechos (core rights) y el ius cogens laboral", Revista del Ministerio de Trabajo y Asuntos Sociales, 72, 2008, 111-151.

Charitsis, Vassilis, Detlev Zwick y Alan Bradshaw, "Creating Worlds that Create Audiences: Theorising Personal Data Markets in the Age of Communicative Capitalism", Triple-C, 16 (2), 2018, 820-834.

\footnotetext{
50 Por función ideológica se entiende a la legitimación del régimen y la fundación de la creencia de que el modo de producción capitalista puede resolver al interior de sus límites sus contradicciones internas. Dichas contra dicciones remiten fundamentalmente a la tensión fundante del sistema, vale decir, la relación dialéctica entre capital y trabajo.

51 Por su parte, la función económica del derecho remite a la reproducción de la estructura misma del modo de producción capitalista. En simple, este se funda sobre la constitución de un mercado mundial. Este se compone por las diferentes naciones, cada una dotada con sus respectivas jurisdicciones, ajustadas estas últimas usualmente al nivel de desarrollo interno de sus fuerzas productivas. De acuerdo a Trotsky, la integración de las diferentes naciones se realiza sobre la división internacional del trabajo. Tal división diferencia naciones extractoras de materias primas (inmaduras económicamente, o subdesarrolladas, o en vías de industrialización) y productoras de mercancías (maduras económicamente, desarrolladas, o industrializadas). No obstante, para que la reproducción de la dominación de una nación sobre otras sea posible es necesario mantener tal diferenciación. Dicha diferenciación únicamente puede sostenerse sobre la base de evitar a toda costa experiencias revolucionarias que devengan en procesos de aceleración del desarrollo de fuerzas productivas, tal como ocurrió en la Unión Soviética y en China tras sus respectivas revoluciones socialistas.

52 Más detalles en Javier Pineda, ¿Qué es la Central Clasista de Trabajadoras y Trabajadores?, Diario El Desconcierto, 2018, Disponible en: http://www.eldesconcierto.cl/2018/09/06/que-es-la-central-clasista-de-trabajadoras-ytrabajadores.
} 
Fuchs, Christian, Digital labour and Karl Marx, Londres, Routledge, 2014.

Gamonal, Sergio, Fundamentos de derecho laboral. Santiago de Chile, LexisNexis, 2008.

Gramsci, Antonio, "El consejo de fábrica". Publicado originalmente en L'Ordine Nouvo", el 5 de junio de 1902. Disponible en:

http://webiigg.sociales.uba.ar/empresasrecuperadas/PDF/PDF_04/consejo4.pdf.

Grez, Sergio, "Un episodio de las políticas del "Tercer Período" de la Internacional Comunista: elecciones presidenciales en Chile, 1931", Historia, 48 (2), 2015, 465-503.

Gudynas, Eduardo, Extractivismos: ecología, economía y política de un modo de entender el desarrollo y la naturaleza, Cochabamba, CEDIB, 2015.

Habermas, Jürgen, Más allá del Estado nacional, Barcelona, Fondo de Cultura Económica, 1999.

Harvey, David, Breve historia del neoliberalismo, Madrid, Akal, 2007.

Izaguirre, Inés, "Acerca de la teoría de las clases y de la lucha de clases. Por qué han sido sustituidas las clases sociales en el discurso académico", Theomai, 29, 2014, 13-37.

Kay, Tamara, "Labor transnationalism and global governance: The impact of NAFTA on transnational labor relationships in North America", American journal of sociology, 111 (3), 2005, 715-756.

Kay, Tamara y Rhonda Evans, Trade Battles: Activism and the Politicization of International Trade Policy, Oxford University Press, 2018.

Knipp, Rocío, Jorge Valdebenito y Andrés Barriga, "No basta con Twittear. \#NoMásAFP ante el sistema de pensiones en Chile", Revista Hipertextos, 9 (6), 2018, 148-184.

Löwy, Michael, Ecosocialismo. La alternativa radical a la catástrofe ecológica capitalista, Buenos Aires, Ediciones Herramienta y Editorial El Colectivo, 2011.

Mandel, Ernest, Control obrero, consejos obreros, autogestión [Antología], Ciudad de México, Era, 1977.

Marx, Karl y Friedrich Engels, El manifiesto comunista, Buenos Aires, Taurus, 2017.

Mascareño, Aldo, "Regímenes jurídicos en la constitución de la sociedad mundial", Política criminal, 2, 2007, 1-39.

Moulian, Tomás, Chile actual. Anatomía de un mito, Santiago de Chile, ARCIS y LOM, 1998.

O'Connell, Paul, "Law, Marxism and Method", Triple-C, 16 (2), 2018, 647-655.

Palomo, Rodrigo, La organización sindical en Chile. XX Jornadas Nacionales de Derecho del Trabajo y la Seguridad Social. Santiago de Chile, Librotecnia, 2014.

Pannekoek, Anton, "Los consejos obreros", Marxist Internet Archive, 2011, Disponible en: https://www.marxists.org/espanol/pannekoek/1940s/consejosobreros/index.htm.

Pérez, Francisco, "El conflicto laboral en la actualidad: Los nuevos conflictos", Ius et praxis, 16 (1), 2010, 441-452.

Salvia, Sebastián, "Alianzas de los empresarios industriales en la crisis del neoliberalismo en Argentina", Revista de sociología e política, 25 (62), 2017, 93-113.

Schweickart, David, After capitalism, Oxford: Rowman and Littlefield, 2002.

Siegle, Lucy, To Die For: Is Fashion Wearing Out the World?, Londres, Fourth state, 2011.

Standing, Guy, "The Precariat: From Denizens to Citizens?", Polity, 44 (4), 2012, 588-608.

Stone, Katherine, "Flexibilization, globalization, and privatization: Three challenges to labour rights in our time", Osgoode Hall Law Journal, 44 (1), 2006, 77-104.

Teague, Paul, "Standard-setting for labour in regional trading blocs: The EU and NAFTA compared", Journal of Public Policy, 22 (3), 2002, 325-348.

Trotsky, León, La revolución permanente, Isla de Maipo, Askasis, 2016.

Ugarte, José Luis, Huelga y derecho, Santiago, Thomson Reuters, 2017.

Van Parijs, Philippe, "Una Renta Básica para todos: asegurar la libertad real, otorgando a todos un ingreso de subsistencia”, Persona y Sociedad, 31 (2), 2017, 197-218. 
Wyczykier, Gabriela, "Sobre procesos de autogestión y recolectivización laboral en la Argentina actual”, Polis, 8 (24), 2009, 197-220.

\section{Referencias electrónicas:}

CECT, "Chile: Derechos humanos o barbarie. Informe 2015 de Derechos Humanos realizado por la Comisión Ética Contra la Tortura”, 2015. Disponible en:

https://notascect.files.wordpress.com/2011/12/informe-2015_23-8-15.pdf.

Harvey, David, El nuevo imperialismo: acumulación por desposesión. Buenos Aires, CLACSO, 2005. Disponible en:

http://www.biblioteca.clacso.edu.ar/gsdl/collect/clacso/index/assoc/D8555.dir/harvey.pdf.

MERCOSUR, Tratado para la constitución de un Mercado Común entre la República Argentina, la República Federativa del Brasil, la República del Paraguay y la República Oriental del Uruguay, 1998. Disponible en: http://www.wipo.int/edocs/trtdocs/es/MERCOSUR/trt_MERCOSUR.pdf.

Nash, Claudio, "Derecho internacional de los derechos humanos en Chile. Recepción y aplicación en el ámbito interno", Centro de Derechos Humanos, Universidad de Chile, 2012. Disponible en: http://repositorio.uchile.cl/bitstream/handle/2250/142503/Derecho-internacional-de-losderechos-humanos-en-Chile.pdf?sequence $=1$.

OCDE, International trade and core labour standards, 2000. Disponible en: https://www.oecd.org/tad/1917944.pdf.

OCDE, Directrices de la OCDE sobre el Gobierno Corporativo de las Empresas Públicas, 2011. Disponible en:

https://www.oecd.org/daf/ca/corporategovernanceofstate-ownedenterprises/48632643.pdf.

OHL, Informe Huelgas Laborales en Chile 2017, 2018. Disponible en: http://www.observatoriodehuelgas.cl.

OIT, Diálogo social tripartito de ámbito nacional. Una guía de la OIT para una mejor gobernanza, 2017. Disponible en: Http://www.ilo.org/wcmsp5/groups/public/---ed_dialogue/--dialogue/documents/publication/wcms_548547.pdf.

OIT, "La negociación colectiva: un principio fundamental, un derecho, un convenio". 1999. Disponible en:

https://www.ilo.org/wcmsp5/groups/public/---ed_dialogue/--actrav/documents/publication/wcms_116092.pdf

Pineda, Javier, ¿Qué es la Central Clasista de Trabajadoras y Trabajadores?, Diario El Desconcierto, 2018, Disponible en: http://www.eldesconcierto.cl/2018/09/06/que-es-la-central-clasista-detrabajadoras-y-trabajadores.

Pulso, DT zanja discusión y declara ilegal la automatización para reemplazo en huelga, 2018. Disponible en: Http://www.pulso.cl/economia-dinero/dt-zanja-discusion-declara-ilegal-laautomatizacion-reemplazo-huelga/.

Stiglitz, Joseph, Democratic development as the fruits of labor, 2000. Disponible en: https://scihub.tw/https://www.jstor.org/stable/pdf/23272436.pdf?seq=1\#page_scan_tab_contents.

Widmyer, Nicholas, "“El pueblo aquí está totalmente humillado". La Contrarreforma Agraria en Chile", Repositorio del Museo de la memoria y los derechos humanos, 2015. Disponible en: http://www.cedocmuseodelamemoria.cl/wp-content/uploads/2015/12/Nicholas-Widmyer.pdf. 